\section{REDUCE OPERATOR WORKLOADS}

Sident Dental Systems' Teneo treatment centre offers many exceptional innovations and is designed to reduce the operator's workload, leaving them free to concentrate on the patient instead.

It offers clinicians simple and intuitive operation via its EasyTouch user interface, wireless foot control for optimum flexibility without cable clutter, intuitive and dynamic seating via the HUGO stool, and an array of patient communication and entertainment tools. For patients, it offers easy access and ergonomic mobility via its innovative chair elevation system, comfortable positioning for patients with restricted mobility, a motor-driven headrest that facilitates optimised positioning of the head, and other feel-good factors including special thermo-upholstery, massage and lumbar support functions.
Teneo's EasyTouch user interface adapts to the clinician's treatment workflows, while its integrated endodontic and implant functions eliminate the need for separate table top units.

Available in three attractive and interchangeable colour schemes, there are also four equipment upgrade options which can be added to the basic configuration in any combination.

Reader response number 53

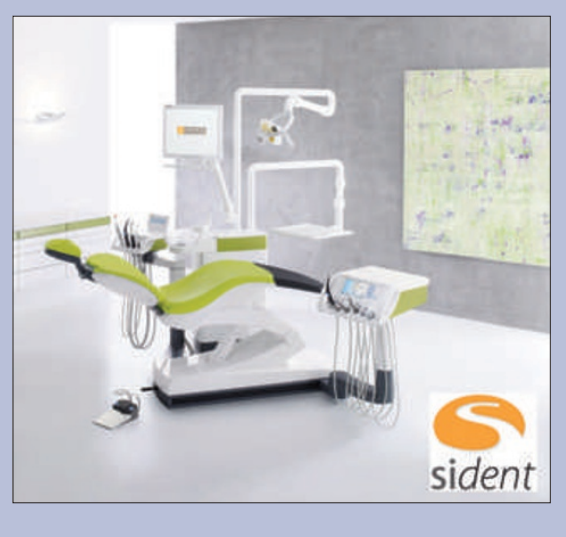

\title{
GENTLE ON THE HANDS, HARD ON BACTERIA
}

PracticeSafe ready to use, tear-resistant, moist wipes are designed for fast cleaning and disinfection of non-sensitive surfaces and objects. These aldehyde and phenol-free wipes from Kemdent are available in 100 piece packs of strong, extra large sheets.

PracticeSafe wipes are low odour, non-drip and durable. They are gentle on the hands but very effective against harmful bacteria and viruses. Used correctly, they guarantee a safe inactiva- tion of influenza A (H1N1) viruses, the pathogens of swine flu.

PracticeSafe wipes provide all dental professionals and their patients with the highest possible level of protection. Unlike paper-based wipes, PracticeSafe wipes hold the disinfectant on the surface of the wipe, enabling the user to clean all surfaces effectively and evenly without the inconvenience of using a soggy wipe.

Reader response number 54

\section{GIVE YOUR OPINION AT SHOWCASE 2010}

The BDTA will be conducting in-depth research amongst visitors at Dental Showcase 2010 in October.

A special research centre will be set up within the hall, complete with terminals where you can give feedback on the major aspects of the event. Participants will receive a Showcase teddy bear to take away with them and will be entered into a prize draw for the chance to win a case of wine.

The research centre is located with the knowledge hunt terminals, making it easy for visitors to take part in both initiatives.

BDTA Dental Showcase 2010 takes place 14-16 October 2010 at ExCeL London. To register in advance for your complimentary ticket visit www. dentalshowcase.com/visit, call the registration hotline on +44 (0) 1494 729959 or text your name, address, occupation and GDC number to 07786 206276. Advance registration closes 1 October 2010.

Reader response number 55

\section{HASSLE-FREE, RISK-FREE, HANDS-FREE}

Dentists can now perform entirely hands-free transfer of dental instruments from chairside through each stage of the decontamination process and back to the chair. Eschmann's all new and improved HFiT Cassettes, with enhanced moisture clearing performance incorporated as standard, come in a range of three different sizes - HFiT 5, HFiT 10 and HFiT 20 - holding five, ten and 20 dental instruments respectively.

Using silicone inserts, available in a choice of six colours, HFiT Cassettes are ideal for managing your instrument inventory whilst promoting more effective instrument traceability. The high quality stainless steel cassettes provide a superior level of performance in comparison to alternative solutions and are constructed to withstand the rigours of the washer disinfection and sterilisation processes.

Compared with similar slim-line versions, HFiT Cassettes have been specifically designed to work with washer disinfectors to pass all relevant soil tests. Their dimensions are optimised to ensure the perfect combination of instrument retention whilst allowing for water pressure agitation to occur, vital for the effective cleaning of all surfaces.

With so many benefits to choose from, an HFiT Cassette will not only significantly reduce the risk of needle stick injuries, it will also save valuable practice time. This is particularly relevant of HFiT 10 Cassettes which can accommodate enough instruments for one patient visit, meaning more effective management of instrument inventory, especially helpful when you are upgrading to a washer disinfection system.

\section{Reader response number 56}

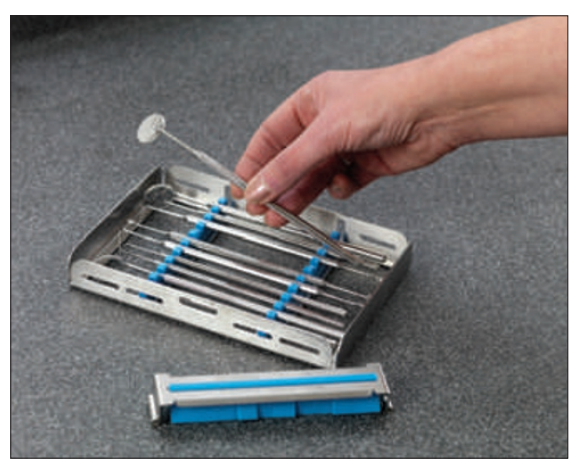

